\section{Flow cytometric analysis of HLA-DR antigen in conjunctival epithelial cells of patients with cystic fibrosis}

${ }^{1}$ Department of Pediatric Ophthalmology Medical University of Bialystok, Bialystok, Poland

\section{${ }^{2}$ Department of Pediatric} Laboratory Diagnostic Medical University of Bialystok, Bialystok, Poland

${ }^{3}$ III Department of Childhood Diseases Medical University of Bialystok Bialystok, Poland

Correspondence: M Mrugacz, Department of Pediatric Ophthalmology, Medical University of Bialystok,

17 Washington Str., 15-274 Bialystok, Poland

Tel: + 48857450862 ;

Fax: + 48857450858

E-mail:mrugacz1@

poczta.onet.pl

Received: 11 October 2005 Accepted in revised form: 21 April 2006 Published online: 19 May 2006

\begin{abstract}
Purpose Cystic fibrosis (CF) is an autosomal-recessive genetic disorder. The disease affects all secretory epithelia including the eye and belongs to the group of ocular surface epithelial diseases, termed keratoconjunctivitis sicca that develop in dry eye. In the pathogenesis of dry eye, inflammation plays a crucial role. The aim of this study was to investigate the expression of HLA-DR on conjunctival epithelial cells from patients with $\mathrm{CF}$.

Materials and methods Twenty-five patients with $C F$ and 25 normal subjects underwent ocular examination. Tear film break-up time (TBUT), Schirmer test, lissamine green staining, and conjunctival impression cytology were carried out. Cells were processed for flow cytometry, by using monoclonal antibodies to HLA-DR.

Results The Schirmer test and TBUT scores were significantly lower in CF patients compared with controls. A significant increase of HLA-DR expression on epithelial cells was found in patients with $\mathrm{CF}$ compared with normal eyes. The Schirmer and TBUT test were positively correlated with HLA-DR expression for the percentage of cells.

Conclusion These results suggest that conjunctival epithelial cells play an important proinflammatory role in ocular changes in CF patients. Our findings confirm the presence of an inflammatory background and the immune nature of this disease. HLA-DR measurement might be a useful method for monitoring of inflammatory processes in the conjunctiva and could be helpful in the use of anti-
\end{abstract}

M Mrugacz'1, J Zak², A Bakunowicz-Lazarczyk', J Wysocka ${ }^{2}$ and $A$ Minarowska ${ }^{3}$ inflammatory drugs in the treatment of ocular findings in CF patients.

Eye (2007) 21, 1062-1066; doi:10.1038/sj.eye.6702435; published online 19 May 2006

Keywords: cystic fibrosis; inflammation; HLA-DR; flow cytometry

\section{Introduction}

Cystic fibrosis (CF) is an autosomal-recessive genetic disorder caused by mutations in the cystic fibrosis transmembrane conductance regulator (CFTR) gene identified on the long arm of chromosome $7 .{ }^{1}$ CFTR is a member of the ATP-binding cassette $(\mathrm{ABC})$ proteins, which functions as a chloride channel in epithelial membranes. ${ }^{2,3}$ The absent or deficient expression of CFTR protein leads to the classic CF phenotype of raised sweat chloride, recurrent respiratory infection with bronchiectasis, and early-onset pancreatic insufficiency. ${ }^{4}$ The most common mutation is the $\Delta \mathrm{F} 508$ mutation, which has a worldwide prevalence of about $70 \%$ of CF chromosomes in Caucasians. ${ }^{5}$ The clinical manifestations of the disease vary greatly between affected individuals, which has led to interest in the relation between genotype and phenotype. ${ }^{6}$

It is presumed that the disease affects all secretory epithelia including the eye. ${ }^{7,8}$ The pathogenesis of ocular changes in CF is still unknown. CF belongs to the group of ocular surface epithelial diseases, termed keratoconjunctivitis sicca (KCS) that develop in dry eye syndrome. The causes of dry eye are multifactorial and can be related to deficiencies 
in any one of the components of the ocular surface and tear film..$^{9}$ It is known that inflammation plays an essential role in the pathogenesis of dry eye..$^{9-15}$

The human conjunctival epithelium is a nonkeratinized squamous tissue composed of three to five layers that cover $80 \%$ of the ocular surface. It has a complex arrangement of microvilli and microplicae and contains goblet cells, Langerhans cells, some lymphocytes, and melanocytes. ${ }^{16-18}$ The most important role of the conjunctival epithelial cells in ocular surface defence and inflammation is its barrier function together with its importance in stabilising the tear film. ${ }^{19}$ However, recent findings suggest that epithelial cells of the conjunctiva may play an active role in inflammation via expression of cell adhesion molecules (ICAM-1) important for leukocyte migration into tissue, and expression of major histocompatibility complex (MHC) class II molecules (HLA-DR) important in antigen presentation and activation of T-lymphocytes. ${ }^{18,20-22}$ HLA-DR expression, normally restricted to immune cells but overexpressed by epithelial cells in the case if immune-driven inflammation, is probably the most relevant factor for investigating ocular surface inflammation. ${ }^{10,20}$

The aim of this study was to investigate in impression cytology (IC) specimens the expression of HLA-DR on conjunctival epithelial cells from patients with CF.

\section{Materials and methods}

Between February and December 2004, 25 patients (13 women, 12 men) from the III Department of Pediatric Diseases, Medical University of Bialystok, Poland, were recruited for this study. The diagnosis of $\mathrm{CF}$ was confirmed by two positive sweat tests and/or a positive CFTR mutation analysis. Most of the CF patients bore the mutation $\Delta \mathrm{F} 508$, either as homozygotes $(n=10)$ or heterozygotes $(n=15)$. Patients were supplemented from diagnosis and regularly monitored by a CF specialist and dietician at least every 2 months. All the patients had a comprehensive assessment every 6-12 months. All patients daily received 8000 IU of vitamin A. Serum vitamin A levels were defined as low if they were under the lower limit of the normal range for our laboratory (1.0-2.4 $\mu \mathrm{mol} / 1$ for subjects under 16 years, and 1.6$2.4 \mu \mathrm{mol} / 1$ for subjects 16 years or over). Serum levels of retinol in CF patients were $2.1 \pm 0.6 \mu \mathrm{mol} / 1$. From the time of examination, the patients were taking pancreatic enzyme supplements and oral ambroxol hydrochloride. Fifteen patients were chronically infected with Pseudomonas aeruginosa and therefore on maintenance treatment with nebulised colistin sulphomethate. The CF patients did not receive any systemic steroid therapy.

Patients with CF attending the III Department of Pediatric Diseases, Medical University of Bialystok, were invited to participate for systemic ophthalmic examination. The ophthalmologic examination included subjective assessment, visual acuity, Schirmer test without anaesthesia, biomicroscopy, tear break-up time (TBUT), and corneal and interpalpebral conjunctival lissamine green staining. All clinical examinations were performed before any topical or systemic treatment was administered to the eye.

To provide normal reference value for the tested markers, 25 normal subjects (12 women, 13 men) were also included and examined by similar procedures. Mean age of the CF group was $14.82 \pm 4.11$ years (range $7-23$ ) vs $15.51 \pm 4.65$ years (range $8-22$ ) in the control group. Only subjects with absolutely normal criteria and not having received any eye drops for at least 3 months were used for normal population analyses.

After topical anaesthesia with one drop of $0.04 \%$ oxybuprocaine, two pieces $13 \times 6.5 \mathrm{~mm}$ in size (polyethersulphone filters, $0.20-\mu \mathrm{m}$ pores, Supor, Gelman Sciences, Ann Arbor, MI, USA) were applied onto the superior and superotemporal bulbar conjunctiva of the both eyes without exerting any pressure. ${ }^{20,23}$ All membranes from each eye were immediately dipped into tubes containing $1.5 \mathrm{ml}$ of cold phosphate-buffered saline (PBS). Monoclonal antibodies conjugated with fluorochromed: antibodies against class II antigen HLA-DR and EpCAM (PerCP-Cy5.5) antigens were purchased from Becton Dickinson (Mountain View, CA, USA). A nonimmune mouse IgG1 was used as a negative isotypic control (Becton Dickinson).

The flow cytometric analysis was performed with a Coulter Epics-XL flow cytometer (Beckman Coulter Corporation, Miami, FL, USA). For each antibody measured, a minimum of 1000 conjunctival cells was acquired. The results were given in percentages of positive cells.

All patients (or their parents) gave their informed consent for collecting impression cytology specimens and processing them by flow cytometry, and all procedures were performed in accordance with the tenets of the Declaration of Helsinki, after approval was obtained from the Ethics Committee of Medical University of Bialystok, Poland.

Statistical comparisons were carried out with Wilcoxon's test, at a 0.05 level of significance.

\section{Results \\ Clinical data}

Twenty-five CF patients, all with mild to moderate KCS were included, and specimens of 25 healthy subjects were also collected as control after a complete clinical examination to assess ocular surface normality. 
Five CF patients and two controls mentioned ocular complaints such as itching, burning, tearing, or matting in the morning. There was no significant difference in ocular complaints between the control and CF populations $(P>0.05)$.

Clinical blepharitis was observed in five CF patients and four control patients. There was no significant difference in ocular complaints between the control and $\mathrm{CF}$ populations $(P>0.05)$.

The Schirmer test scores realised in both eyes in the two groups were significantly lower in CF patients (mean \pm SD, $9.68 \pm 5.54 \mathrm{~mm}$ ) compared with those obtained from subjects in the control group $(25.21 \pm 3.08 \mathrm{~mm})(P<0.001)$.

Compared with the control group, CF patients showed significantly lower TBUT $(9.9 \pm 1.1$ and $5.3 \pm 2.6 \mathrm{~s}$, respectively) $(P<0.0001)$.

The lissamine green score was not significantly different between CF patients and controls $(0.48 \pm 0.65$ and $0.52 \pm 0.65$, respectively).

\section{Flow cytometry results}

HLA-DR was expressed in $16.93 \pm 10.33 \%$ of the cells from the CF group: the expression of HLA-DR in a cohort of CF subjects who are $P$. aeruginosa free and have not received nebulised antibiotic was $16.21 \pm 9.93 \%$ and in patients with infection $16.99 \pm 10.41 \%$. In contrast, HLA-DR was expressed in $8.10 \pm 1.94 \%$ of the cells from healthy control subjects. The mean percentage of HLA-DR-positive cells was significantly higher in the CF group compared with the normal group $(P=0.0019)$.

\section{Correlation analyses}

All data are summarised in Table 1. The Schirmer and TBUT test were positively correlated with HLA-DR expression for the percentage of cells $(P=0.018$ and $P=0.0076$, respectively). There was no correlation between ocular complaints, clinical blepharitis, the

Table 1 Correlations of clinical tests and HLA-DR expression

\begin{tabular}{|c|c|c|}
\hline & $R$ & P-value \\
\hline $\begin{array}{l}\text { Ocular complaints, \% HLA-DR-positive } \\
\text { cells }\end{array}$ & -0.192 & 0.416 \\
\hline $\begin{array}{l}\text { Clinical blepharitis, \% HLA-DR-positive } \\
\text { cells }\end{array}$ & -0.166 & 0.482 \\
\hline Schirmer test, \% HLA-DR-positive cells & 0.522 & 0.018 \\
\hline TBUT, \% HLA-DR-positive cells & 0.577 & 0.0076 \\
\hline $\begin{array}{l}\text { Lissamine green score, \% HLA-DR-positive } \\
\text { cells }\end{array}$ & 0.377 & 0.100 \\
\hline
\end{tabular}

TBUT, tear break-up-time; R, coefficient of correlation. lissamine green score, and HLA-DR expression (0.416, 0.482 , and 0.100 , respectively).

\section{Discussion}

In the present work, we investigated the ocular surface of patients with CF and with functional and clinical ocular signs. For a better understanding of the implication of dry eye on the ocular surface in CF patients, we also studied the epithelial cell status of patients with CF.

In our study, the Schirmer and TBUT tests were significantly decreased in CF group, thus suggesting effects on tear film stability and secretion as already described in $\mathrm{CF}^{24,25}$ We have shown that HLA-DR expression in conjunctival epithelium in CF patients is upregulated compared with healthy control subjects.

HLA-DRs, class II MHC molecules, are cell-surface receptors mediating antigen presentation to immunocompetent cells. Conjunctival epithelial cells express HLA-DR during immune-mediated cell activation and in inflammatory conditions. ${ }^{22,26}$

HLA-DR expression has been reported to be greater in dry eye, chronic conjunctivitis, and patients with Sjogren's syndrome. ${ }^{18,20,27,28}$ According to Tsubota et $a l^{18,28}$ HLA-DR upregulation could be an additional mechanism of ocular surface cell destruction by immunologic reaction, increasing the alteration of the ocular surface as a result of desiccation in patients with Sjogren's syndrome and may be regulated by IFN- $\gamma$ through the activation of nuclear factor-kappa B (NF- $\kappa \mathrm{B})$. In the another study, HLA-DR expression was found at significantly higher level in eyes with SS than in KCSaffected eyes without SS. ${ }^{10} \mathrm{KCS}$ and ocular rosacea were associated with overexpression of inflammatory markers such as HLA-DR and ICAM-1 and a significant decrease in the number of goblet cells. ${ }^{29}$ Thus, in rosacea, inflammation of the ocular surface was clearly demonstrated with an increase of inflammatory mediators as interleukin (IL)- $1 \alpha^{30}$ or gelatinase B activity in tears of patients. ${ }^{31}$ Hingorani et $a l^{32}$ found a greater expression of HLA-DR in conjunctival epithelial cells in the different chronic ocular allergic disorders such as vernal keratoconjunctivitis (VKC) and atopic keratoconjunctivitis (AKC). Whether HLA-DR + epithelial cells from conjunctiva are able to present antigen, and perhaps influence the proliferation of specific T-cell subtypes, is at present unknown. The fact that in vitro conjunctival epithelium expresses HLA-DR, ICAM-1, CD40, and E-cadherin could suggest its role in initiation and regulation of ocular surface responses as well as its antigen-presenting properties. ${ }^{33}$

Increased expression of HLA-DR and ICAM-1 has been reported in contact lens wearers compared to 
normal eyes, ${ }^{29}$ suggesting the possibility that contact lens use could cause inflammation of the conjunctiva.

Our findings of a large number of HLA-DR + conjunctival cells in CF patients confirm the presence of an inflammatory background and the immune nature of this disease. However, our results show that ocular changes are intrinsic in CF and not related to treatment, nutritional deficiency, or even infection. HLA-DR measurement might be a useful method for monitoring the level of activation of inflammatory process in the conjunctiva in patients with CF. It could be helpful in the diagnosis and the use of anti-inflammatory drugs, in addition to tear substitutes, in the treatment of ocular changes in $\mathrm{CF}$ patients.

\section{Acknowledgements}

We thank Professor Christophe Baudouin MD, PhD, Service d'Ophthalmologie III, Ctr Hospital National des Quinze-Vingts, Paris, France, for helpful advice. This work was supported by a grant from The Polish State Committee for Scientific Research (KBN; No. 3 P05E 047 25).

\section{References}

1 Riodan JR, Rommens JM, Kerem BS. Identification of the cystic fibrosis gene: cloning and characterization of complementary DNA. Science 1989; 245: 1066-1073.

2 Mc Kone EF, Emerson SS, Edwards KL, Aitken ML. Effect of genotype on phenotype and mortality in cystic fibrosis: a retrospective cohort study. Lancet 2003; 361: 1671-1676.

3 Nagel G. Differential function of the two nucleotide binding domains on cystic fibrosis transmembrane conductance regulator. Biochim Biophys Acta 1999; 1461: 263-274.

4 Welsh MJ, Anderson MP, Rich DP. Cystic fibrosis, CFTR and abnormal electrolyte transport. In: Davis PB (eds). Lung Biology in Health and Disease. Marcel Dekker: New York, 1993 pp 29-32.

5 Kerem BS, Rommens JM, Buchanan JA. Identification of the cystic fibrosis gene: genetic analysis. Science 1989; 245: 1073-1080.

6 Mickle JE, Cutting GR. Genotype-phenotype relationships in cystic fibrosis. Med Clin N Am 2000; 84: 597-607.

7 Castagna I, Roszkowska AM, Fama F, Sinicropi S, Ferreri G. The eye in cystic fibrosis. Eur J Ophthalmol 2001; 11: 9-14.

8 Turner HC, Bernstein A, Candia OA. Presence of CFTR in the conjunctival epithelium. Curr Eye Res 2002; 24: 182-187.

9 Baudouin C. The pathology of dry eye. Surv Ophthalmol 2001; 45: 211-220.

10 Brignole F, Pisella PJ, Goldshild M, De Saint Jean M, Goguel A, Baudouin C. Flow cytometric analysis of inflammatory markers in conjunctival epithelial cells of patients with dry eyes. Invest Ophthalmol Vis Sci 2000; 41: 1356-1363.

11 Brignole F, Pisella PJ, Goldshild M, De Saint Brignole F, Pisella PJ, De Saint Jean M et al. Flow cytometric analysis of inflammatory markers in KCS: 6-month treatment with topical cyclosporin A. Invest Ophthalmol Vis Sci 2001; 42: 90-95.
12 Gao J, Morgan G, Tieu D, Schwalb TA, Luo JY, Wheeler LA et al. ICAM-1 expression predisposes ocular tissue to immune-based inflammation in dry eye patients and Sjogrens syndrome-like MRL/lpr mice. Exp Eye Res 2004; 78: 823-835.

13 Pflugfelder SC. Antiinflammatory therapy for dry eye. Am J Ophthalmol 2004; 137: 337-342.

14 Pisella PJ, Brignole F, Debbasch C, Pharm D, Lozato PA, Creuzot-Garcher $\mathrm{C}$ et al. Flow cytometric analysis of conjunctival epithelium in ocular rosacea and keratoconjunctivitis sicca. Ophthalmology 2000; 107: 1841-1849.

15 Stern ME, Gao J, Siemasko KF, Beuerman RW, Pflugfelder $\mathrm{SC}$. The role of the lacrimal functional unit in the pathophysiology of dry eye. Exp Eye Res 2004; 78: 409-416.

16 Bron AJ, Mengher LS, Davey CC. The normal conjunctiva and its responses to inflammation. Trans Ophthalmol 1985; 104: 424-434.

17 Records RE. The conjunctiva and lacrimal system. In: Duane TD, Jaeger EA (eds). Biomedical Foundations of Ophthalmology. JB Lippincott Co.: Philadelphia, USA, 1998 pp 1-21.

18 Tsubota K, Fujihara T, Saito K, Takeuchi T. Conjunctival epithelium expression of HLA-DR in dry eye patients. Ophthalmologica 1999; 213: 16-19.

19 Chandler JW, Gillette TE. Immunologic defense mechanisms of the ocular surface. Ophthalmology 1983; 90: 585-591.

20 Baudouin C, Brignole F, Becquet F, Pisella PJ, Goguel A. Flow cytometry in impression cytology specimens. A new method for evaluation of conjunctival inflammation. Invest Ophthalmol Vis Sci 1997; 38: 1458-1464.

21 Stern ME, Gao J, Schwalb TA, Ngo M, Tieu DD, Chan CC et al. Conjunctival T-cell subpopulations in Sjogren's and non-Sjogren's patients with dry eye. Invest Ophthalmol Vis Sci 2002; 43: 2609-2614.

22 Zhan H, Towler HM, Calder VL. The immunomodulatory role of human conjunctival epithelial cells. Invest Ophthalmol Vis Sci 2003; 44: 3906-3910.

23 Calonge M, Diebold Y, Saez V, de Salamanca AE, GarciaVazquez C, Corrales RM et al. Impression cytology of the ocular surface: a review. Exp Eye Res 2000; 78: 457-472.

24 Morkeberg JC, Edmund C, Prause JU, Lanng S, Koch C, Michaelsen KF. Ocular findings in cystic fibrosis patients receiving vitamin A supplementation. Exp Eye Res 1995; 233: 709-713.

25 Shepard JD, Orenstein DM, Chao ChCh, Butala S, Kowalski RP. The ocular surface in cystic fibrosis. Ophthalmology 1989; 96: 1624-1630.

26 Brignole-Baudouin F, Ott AC, Warnet JM, Baudouin C. Flow cytometry in conjunctival impression cytology: a new tool for exploring ocular surface pathologies. Exp Eye Res 2004; 78: 473-481.

27 Jones D, Monroy D, Ji Z, Atherton SS, Pflugfelder SC. Sjogren's syndrome: cytokine and Epstein-Barr viral gene expression within the conjunctival epithelium. Invest Ophthalmol Vis Sci 1994; 35: 3493-3504.

28 Tsubota K, Fukagawa K, Fujihara T, Shimmura S, Saito I, Saito K et al. Regulation of human leukocyte antigen expression in human conjunctival epithelium. Invest Ophthalmol Vis Sci 1999; 40: 28-34.

29 Pisella PJ, Brignole F, Lejeune S, Brignole F, Debbasch C, Bara J et al. Ocular surface changes induced by contact lens wear. Cornea 2001; 20: 820-825. 
30 Barton K, Monroy DC, Nava A, Pflugfelder SC. Inflammatory cytokines in the tears of patients with ocular rosacea. Ophthalmology 1997; 104: 1868-1874.

31 Afonso AA, Sobrin L, Monroy DC. Tear fluid gelatinase B activity correlates with IL-1 alpha concentration and fluorescein clearance in ocular rosacea. Invest Ophthalmol Vis Sci 1999; 40: 2506-2512.
32 Hingorani M, Calder V, Buckley RJ, Lightman SL. The role of conjunctival epithelial cells in chronic ocular allergic disease. Exp Eye Res 1998; 67: 491-500.

33 Clayton A, Court J, Navabi H, Adams M, Mason MD, Hobot JA et al. Analysis of antigen presenting cell derived exosomes, based on immuno-magnetic isolation and flow cytometry. J Immunol Meth 2001; 247: 163-174. 